\title{
Establishing Rules and Conventions for the Infrastructure: The Tragedy of the Unmanaged Commons as a Determinate Factor
}

\author{
Rob Reilly and Barry Kort \\ M.I.T. Media Laboratory \\ \{reilly,bkort\}@media.mit.edu
}

\begin{abstract}
As computer networks become the media through which more and more public discourse takes place, the ways in which that discourse is socially organized becomes more consequential. [Kollock and Smith 1994]. It would seem prudent to consider addressing the issues of social interaction and social behavior on the network based upon the concept of Hardins tragedy of the commons [Hardin, 1968] in which he described a group of herders having open access to a common parcel of landknown as the Common (or town common)on which they could let their cows graze. It is in each herders interest to put as many cows as possible onto the common, even if the common is damaged as a result. The herder receives all the benefits from the additional cows and the entire group shares the damage to the common. Yet if all herders make this individually reasonable decision the commons is destroyed and all will suffer.

Hardins model when coupled with a foundational understanding of the structure, function, and purpose of any online electronic mechanism will prove to be a powerful model by which to establish rules and conventions for the infrastructure.
\end{abstract}

\section{Managing the Electronic Commons}

In 1968, biologist Garrett Hardin brought to sciences attention a little-known work by the nineteenth century amateur mathematician William Forster Lloyd on population growth and control. Lloyd examined the fate of a common pasture shared among rational, utility-maximizing herdsmen [Turner, 1991].

Shepherds grazed sheep on the individual parcels of land they owned. But there was another pasture, a large public stretch of land held in reserve, owned in common by the villagers and known, logically enough, as the Common. Then, some shepherds became greedy. They began guiding their sheep to the Common each day, preferring to wear out the public pasture because they thought it cost them nothing and saved their own small patches. Soon, others joined in, unwilling to deplete their lands while a few neighbors took advantage of the public lands. It wasn't long before the Common was turned into a muddy wastelanduseless to anyone. And as the shepherds watched their individual pastures fall to overgrazing, they realized that its own people had sacked their village. Theyd stolen their shared livelihood, economic security, cultural center, and much of their villages beauty from themselves and their children [Hardin, 1968].

Once a resource is being utilized at a rate near its carrying capacity, additional utilization will degrade its value to its current users. Users then will enter into a cycle of additional use of the resource to gain or to try to break even, as others use it. Since all users engage in this behavior, the resource is ultimately and inevitably doomed.

The inexorable working out of the resources ruin is Hardin's Tragedy of the Common. In human affairs, the tragedy of the common has never been more evident than it is today. Its effects are pollution, global warming, ozone depletion, over fishing and extinction of species, abuse of aquifers, and destruction of the rain forests. 
But what relevance does this have to social interaction in cyberspace?

This is relatively easy as, at the heart of these models/research projects, is the problem of the free-rider or the over grazer, and the issue of regulating use and behavior of a shared resource.

As Ostrom [1990] notes, the challenge becomes how a group can organize and govern themselves to obtain collective benefits in situations where the temptations to free-ride and/or to break commitments are substantial. Ostrom [1990] studied a wide range of communities which had a long history of successfully producing and maintaining collective goods. She also studied a number of communities which had failed partially or completely in meeting this challenge [Kollock and Smith, 1994]. In comparing the communities, Ostrom [1990] found that groups that are able to organize and govern themselves are marked by the following design principles:

- Group boundaries are clearly defined

- $\quad$ Rules governing the use of collective goods are well matched to local needs and conditions

- Most individuals affected by these rules and policies can participate in modifying the rules ad policies

- The rights of community members to devise their own practices is respected by external authorities

- A system for monitoring members behavior exists; this monitoring is undertaken by the community members themselves

- A graduated system of remediation is used

- $\quad$ Community members have access to low-cost conflict resolution mechanisms.

Applying Ostroms observations along with a foundational understanding of the legal principles of privacy, search and seizure, and due process seems to provide a powerful model upon which the crafting of a social metaphor, which will, in-turn, serve a the basis for a social contract or at least a social norm for interactions in cyberspace.

\section{The Social Contract - A Transformational Approach}

We should explore the use a social contract. The underlying rules and conventions should be crafted/established, as other social contracts are (e.g., the US Constitution, a faculty handbook, a student handbook). Those who craft/ establish the rules and conventions for the infrastructure should certainly consider the logistical needs inherent in maintaining a secure and functional computer network.

The rules and conventions, policies and procedures can be a way to manage the electronic common that will preserve the power of cooperation without infringing on individual freedom or the growth of knowledge and wisdom of which the Net is capable. The collective intelligence of the Net ought to get a chance to activate a social immune response before too many people who dont know exactly what they are panicking about call for a police force we dont need [Rheingold, 1996].

There is a more-or-less subtle, but nonetheless, transformational change that those who craft/establish rules and conventions for the infrastructure should undergo. They should shift their paradigm from one which views the management or establishment of the infrastructure as a document (written or unwritten) that informs the user primarily of what the technical and logistical requirements of computer network usage are (which most already do) to one which includes the view that a social contract is also part of the infrastructure:

- that is crafted for a demographically diverse community,

- that will facilitate the development of community, which will, in turn, facilitate the establishment of community-endorsed ethics and values.

- creating statements that treat computer network actions in the same manner that they would be treated if they occurred in the real world, and,

- providing a foundational basis for addressing and resolving social issues/dilemmas that may develop.

Let me conclude that protocols need to be in place to manage social interactions in future, and existing electronic artifacts. These social contracts that underpin/support the infrastructure should be developed with a foundational 
understanding of: legal principles of privacy, search and seizure, and due process, and, theory of management of commonly shared resources and the inherent questions of social order.

Our message is to reinforce the idea that a social consciousness must be in the foreground. We are not offering specific strategies for implementing our position, we are offering a philosophical idea. You may be looking for us to offer specifics, but the specifics rest with you, they rest with those who will create, we offer the idea that a moral compass is needed.

\section{References}

[1] Hardin, Garrett. (1968). The tragedy of the commons. Science (162), page 1243-1248.

[2] Kollock, Peter, and Marc Smith. (1994). Managing virtual communities: Cooperation and conflict in computer communities [On-line]. As of May 2001: http://www.sscnet.ucla.edu/soc/csoc/vcommons.htm.

[3] Ostrom, Elinor. (1990). Governing the commons: The evolution of institutions for collective action. New York: Cambridge University Press.

[4] Rheingold, Howard. (1996, June 15). Federal judges defend free speech on the Internet [Online]. Posted to the Virtual Communities Conference on the WELL (Whole Earth Lectronic Link), San Francisco, CA.

[5] Turner, Roy M. (1991, January). The tragedy of the commons and distributed AI systems [Online]. Paper presented at the 12th International Workshop on

Distributed Artificial Intelligence, University of New Hampshire, Durham, NH. Available as of May 2001: http:// cdps.umcs.maine.edu/Papers/1993/TofCommons/TR.html. 